"Fl suler ide mis hiipses

Año 13.

Núm. 34 Tema COVID 19

Especial

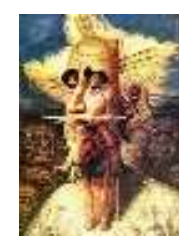

Revista de Investigación

Académica sin Frontera

ISSN: 2007-8870

https://revistainvestigacionacademicasinfrontera.unison.mx/index.php/RDIASF

Recibido el 13 de noviembre de 2020. Dictaminado mediante arbitraje favorablemente 30 de diciembre de 2020.

\title{
Contingencia sanitaria por COVID-19 y su impacto en la modalidad del proceso de enseñanza-aprendizaje
}

\section{Health contingency due to COVID-19 and its impact on the modality of the teaching- learning process}

\author{
Alfonso López Corral \\ https://orcid.org/0000-0003-2557-808X \\ alfonso.lopez@unison.mx. \\ Karla Fabiola Acuña \\ https://orcid.org/0000-0002-1704-4240
}

Universidad de Sonora

\section{Resumen}

El cambio abrupto en la modalidad del proceso de enseñanza-aprendizaje debido a la pandemia por COVID-19 puso de manifiesto las carentes habilidades que tienen tanto profesores como estudiantes en el uso de la tecnología. Su inclusión en la enseñanza universitaria ha supuesto mejorías, aunque incipientes en los diferentes espacios educativos. En el presente manuscrito se muestran algunos estudios acerca de la percepción que tienen profesores y estudiantes de su impacto en los contextos tanto en línea como combinados, que muestran que las prácticas educativas no se han modificado sustancialmente. Finalmente, se discute que una verdadera tecnología educativa deberá construirse a partir de investigación, reflexión y análisis desde un abordaje interdisciplinario de los procesos educativos mediados a través de las TIC; cualquier aportación que se lleve a cabo desde el ámbito de la Psicología deberá considerar marcos de teoría 
Año 13.

Núm. 34 Tema COVID 19

Especial
Académica sin Frontera

ISSN: 2007-8870

\title{
https://revistainvestigacionacademicasinfrontera.unison.mx/index.php/RDIASF
}

Recibido el 13 de noviembre de 2020. Dictaminado mediante arbitraje favorablemente 30 de diciembre de 2020.

general que permitan entender las modulaciones de comportamiento (qué y cómo aprender) ante las circunstancias que han impuesto las nuevas modalidades de enseñanza.

Palabras clave: Tecnologías de la información y la comunicación, pandemia, psicología, tecnología educativa, enseñanza, aprendizaje.

\begin{abstract}
The abrupt change in the modality of the teaching-learning process due to the situation within COVID-19 revealed the lack of skills that both teachers and students have in the use of technology. Its inclusion in higher education has led to improvements, although incipient in the different educational settings spaces. The present manuscript shows some studies about the perception that both teachers and students have of its impact in both online and combined contexts, which show that educational practices have not been substantially modified. Finally, a true educational technology must be built from research, reflection and analysis based on an interdisciplinary approach to educational processes mediated through information and communications technology (ICT); Any contribution that is carried out from the field of Psychology should be consider general theory frameworks that allow the understanding of behavioral modulations in the face of the circumstances that have imposed new teaching modalities.
\end{abstract}

Key words: information and communications technology, pandemic, psychology education technology, teaching, learning. 
Año 13.

Núm. 34 Tema COVID 19

Especial
Académica sin Frontera

ISSN: 2007-8870

\section{https://revistainvestigacionacademicasinfrontera.unison.mx/index.php/RDIASF}

Recibido el 13 de noviembre de 2020. Dictaminado mediante arbitraje favorablemente 30 de diciembre de 2020.

\section{Introducción}

La Organización Mundial de la Salud (OMS) declaró pandemia el brote de COVID-19 al extenderse y multiplicarse el número de contagios a otros países tras su detección en China a finales de 2019. De acuerdo con este organismo, el SARS- Cov2 (COVID-19) pertenece a la familia de los coronavirus, los cuales pueden causar enfermedades tanto en animales como en humanos. En humanos, pueden causar infecciones respiratorias que van desde el resfriado común hasta enfermedades graves, como el síndrome respiratorio de Oriente Medio (MERS) o el síndrome respiratorio agudo severo (SRAS). Los síntomas más comunes detectados de COVID-19 son fiebre, tos seca y cansancio y, entre los menos frecuentes, dolores y molestias, congestión nasal, dolor de cabeza, dolor de garganta, diarrea, pérdida del gusto o el olfato, conjuntivitis y erupciones cutáneas; en un bajo porcentaje, estas manifestaciones clínicas pueden agudizarse, volverse graves y causar incluso la muerte.

A raíz de la declaración de Pandemia, la OMS señaló que los países deben activar y ampliar los mecanismos de respuesta a emergencias, comunicarse con la población sobre los riesgos y formas de protección, así como encontrar, aislar, probar y tratar cada caso de COVID-19 y rastrear a las personas con las que una persona infectada haya estado en contacto. Las medidas generales que han adoptado la mayoría de los países son la implementación de cuarentena, aislamiento y distanciamiento físico. La cuarentena significa restringir las actividades o separar a las personas que no están enfermas pero que pueden haber estado expuestas a COVID-19. El aislamiento significa separar a las personas que están enfermas con síntomas de COVID-19 y pueden ser contagiosas para prevenir la propagación de la enfermedad. Por último, el distanciamiento físico 
Año 13.

Núm. 34 Tema COVID 19

Especial
Académica sin Frontera

ISSN: 2007-8870

\section{https://revistainvestigacionacademicasinfrontera.unison.mx/index.php/RDIASF}

Recibido el 13 de noviembre de 2020. Dictaminado mediante arbitraje favorablemente 30 de diciembre de 2020.

significa estar físicamente separado; es decir, se recomienda mantener una distancia de al menos un metro con los demás, la cual es una medida general que todas las personas deberían adoptar incluso si se encuentran bien y no han tenido una exposición conocida a este virus.

La contingencia sanitaria representa a nivel mundial un reto para la sociedad no sólo en términos de salud, sino económicos, políticos, educativos y psicológicos, entre otros, pues ya se comienzan a prever los efectos que el COVID-19 tendrá en todos los niveles. En cuanto a su impacto psicológico, como señalan Shigemura et al. (2020), se pueden esperar consecuencias físicas y mentales, sobre todo en poblaciones vulnerables y de riesgo. Primero, las respuestas emocionales probablemente incluirán miedo e incertidumbre. Enseguida, se pueden suscitar comportamientos sociales negativos inducidos por el miedo y una falsa percepción de riesgo. Estas experiencias pueden incluir un amplio rango de problemas que afecten la salud mental (insomnio, ira, miedo al contagio aun cuando no haya habido alguna exposición), conductas de riesgo (incremento en el uso de alcohol y tabaco, aislamiento social) y desórdenes mentales (estrés postraumático, depresión, somatización). Sin embargo, los efectos psicológicos particulares que tendrá sobre la población están en curso de ser evaluados, como se constata con las encuestas y cuestionarios que comienzan a hacerse vía Internet por parte de instituciones públicas y privadas.

Predicciones como las de Shigemura et al. (2020) se vuelven no sólo pertinentes sino necesarias si se revisan estudios que investigan el impacto psicológico sobre la población en eventos similares (Torales, O’Higgins, Castaldelli- Maia \& Ventriglio, 2020). Brooks et al. (2020), hicieron una revisión de 24 investigaciones que evaluaron el impacto psicológico de la cuarentena en pandemias como SARS, MERS, H1N1, Ébola, entre otras. En la mayoría de los estudios que revisaron se reportan efectos psicológicos negativos asociados con la cuarenta, como ansiedad, estrés, depresión, insomnio, irritabilidad, síntomas de estrés postraumático, ira, agotamiento emocional, entre otros. Identifican como estresores durante la cuarentena: la duración, temor al 
Año 13.

Núm. 34 Tema COVID 19

Especial
Académica sin Frontera

ISSN: 2007-8870

\section{https://revistainvestigacionacademicasinfrontera.unison.mx/index.php/RDIASF}

Recibido el 13 de noviembre de 2020. Dictaminado mediante arbitraje favorablemente 30 de diciembre de 2020.

contagio (tanto para sí, como para familiares), frustración y aburrimiento, suministros o provisiones inadecuados o insuficientes (alojamiento, agua, comida, ropa, citas médicas, etc.), así como información confusa o insuficiente. Como estresores posteriores a la cuarentena: ira y ansiedad; estigmatización y rechazo (por ejemplo, en médicos o enfermeras) y problemas financieros (por ejemplo, personas que dejaron de trabajar o perdieron sus trabajos por la contingencia) que pueden ser factor de riesgo para trastornos psicológicos. Por último, proporcionan algunas recomendaciones para mitigar los efectos de la cuarentena: limitar su duración en la medida de lo posible, información entendible por parte de las autoridades sobre la enfermedad y los motivos de la cuarentena, proporcionar suministros y provisiones adecuadas, reducir el aburrimiento mediante actividades positivas y mejorar el trato que los trabajadores de la salud deben recibir.

\section{Planteamiento del problema}

En México, el 31 de marzo de 2020, el Consejo de Salubridad General declaró la emergencia sanitaria nacional por causa de fuerza mayor a la epidemia de enfermedad generada por el virus SARS-CoV-2 y se acordaron medidas extraordinarias en todo el territorio nacional, entre las que se destacaron la suspensión inmediata, por un mes, de actividades no esenciales en los sectores público, privado y social, con la finalidad de mitigar la dispersión y transmisión del virus SARSCoV-2 en la comunidad, para disminuir la carga de enfermedad, sus complicaciones y muerte por COVID-19 en la población residente en el territorio nacional y evitar la saturación del sistema de salud en su red hospitalaria.

De acuerdo con la declaratoria de emergencia, las clases a nivel básico y media superior fueron primero suspendidas y, posteriormente al retorno vacacional por Semana Santa, se acordó su regreso en modalidad a distancia y en esta condición finalizó el ciclo escolar 2019-2020. A nivel superior las universidades no suspendieron clases, sino que desde la declaración de emergencia 
Año 13.

Núm. 34 Tema COVID 19

Especial
Académica sin Frontera

ISSN: 2007-8870

\section{https://revistainvestigacionacademicasinfrontera.unison.mx/index.php/RDIASF}

Recibido el 13 de noviembre de 2020. Dictaminado mediante arbitraje favorablemente 30 de diciembre de 2020.

migraron las clases a una modalidad totalmente a distancia y, al igual que en el nivel básico y media superior, finalizaron de esa manera el semestre o año escolar. Debido a esto, los maestros de todos los niveles educativos que enseñaban bajo una modalidad presencial tuvieron que recurrir a prácticas pedagógicas de carácter complementario, que iban desde los que podían retomar su curso mediante una plataforma educativa alojada en la red, dar la clase por videoconferencia, quienes implementaron un contacto con sus alumnos por redes sociales no diseñadas para objetivos educativos (por ejemplo, contacto por WhatsApp), hasta quienes pidieron la acumulación y escaneo de cierto número de tareas (creación de carpetas) para enviarse vía correo electrónico, por mencionar sólo algunas.

Al persistir las condiciones de emergencia y no haberse levantado las restricciones para la mayoría de las actividades, las autoridades de la Secretaría de Educación y Cultura anunciaron que el comienzo del ciclo escolar 2020-2021 sería también en modalidad a distancia, al menos hasta no existir las condiciones para un regreso seguro y controlado a las aulas. Puede decirse que la implementación de la modalidad a distancia agregó estresores adicionales para las personas durante la contingencia, en específico a padres, estudiantes y maestros. A esto se sumó una preocupación general, que tiene que ver con que si el cambio apresurado de modalidad tendrá repercusiones en el aprendizaje de los estudiantes.

Conocer los efectos generales que eventos similares han causado y los datos que sobre el mismo se van generando, permite determinar estrategias de contención e intervención en varios niveles. Al reconocer que los efectos de una contingencia sanitaria van más allá de la prevención de la enfermedad y de la búsqueda de una vacuna, se pueden identificar las necesidades de las personas y ofrecerles el apoyo y la asistencia específica que realmente necesitan durante la contingencia y posteriormente. Los efectos psicológicos que la pandemia y las medidas de aislamiento y cuarentena provocan, como se infiere de los estudios citados, son diversos, pues no 
Año 13.

Núm. 34 Tema COVID 19

Especial
Académica sin Frontera

ISSN: 2007-8870

\section{https://revistainvestigacionacademicasinfrontera.unison.mx/index.php/RDIASF}

Recibido el 13 de noviembre de 2020. Dictaminado mediante arbitraje favorablemente 30 de diciembre de 2020.

es sólo el temor, racional o irracional al contagio, el que puede afectar como estresor y provocar algún trastorno. La cuarentena, por su duración, se vuelve un factor importante, toda vez que puede relacionarse con otros estresores, como la preocupación por provisiones o suministros o la pérdida de ingresos económicos. Aún más, deben considerarse los estresores posteriores, como el duelo en personas que perdieron a un familiar o amigo a causa del virus, y posibles efectos, como estrés postraumático.

Respecto a las medidas de aislamiento y cuarentena, entre el impacto psicológico que puede tener, deben considerarse otros aspectos. Si ya se reconoce, por ejemplo, como estresores a los problemas financieros o la preocupación laboral, así como la preocupación por suministros adecuados, a estos debe sumarse el cambio de situación escolar al extenderse más de lo previsto la cuarentena, es decir, los escolares de todos los niveles deben ahora estudiar desde casa, estén o no preparados para ello, cuenten o no con los medios necesarios; al mismo tiempo, los maestros de todos los niveles deben enseñar desde casa, estén o no habilitados para ello, cuenten o no con los medios necesarios. Esto representaría un problema de índole educativa, y al mismo tiempo de índole psicológica. Dado el cambio abrupto en la modalidad del proceso de enseñanza-aprendizaje, el objetivo del presente manuscrito es revisar y analizar algunos estudios acerca de la percepción que tienen profesores y estudiantes de su impacto en los contextos tanto en línea como combinados, que muestran que las prácticas educativas no se han modificado sustancialmente y, finalmente, analizar algunas variables indispensables para el aprendizaje independientemente de la modalidad de enseñanza.

\section{Efectos de la pandemia en el proceso de enseñanza-aprendizaje}

El informe que presenta la UNESCO-IESALC (2020) de los efectos inmediatos y al día después del COVID-19 en la educación superior, se prevé que el impacto será a corto, mediano y largo plazo, afectando principalmente a: 
Año 13.

Núm. 34 Tema COVID 19

Especial
Académica sin Frontera

ISSN: 2007-8870

\section{https://revistainvestigacionacademicasinfrontera.unison.mx/index.php/RDIASF}

Recibido el 13 de noviembre de 2020. Dictaminado mediante arbitraje favorablemente 30 de diciembre de 2020.

a) Estudiantes: hay indicadores (aunque no definitivos ${ }^{1}$ ) que permiten anticipar que en Iberoamérica las preocupaciones se centran en tres aspectos: la conectividad a internet (como una condición que promueve la desigualdad), las cuestiones financieras y las dificultades para mantener un horario regular que probablemente se relaciona con hábitos de estudio no idóneos, y que no fomentan la autorregulación de los aprendizajes.

b) Profesorado: la preocupación por la continuidad laboral se destaca, ya que se reconoce que, en su mayoría, la docencia universitaria con dedicación exclusiva no está generalizada y predomina la dedicación a tiempo parcial (p.e. profesores de asignatura); enseguida, la expectativa, sino es que exigencia, de la continuidad de la actividad docente bajo la modalidad virtual sobre todo en materias que buscan el desarrollo de competencias profesionales (por ejemplo, las prácticas de campo, residencias, servicio social, entre otros).

c) Instituciones de educación: el impacto dependerá de su capacidad para mantenerse activas en sus actividades académicas (sobre todo en instituciones privadas) y, en segundo lugar, de su sostenibilidad financiera.

Por supuesto, el efecto no se reduce a estudiantes, profesores y escuelas. Barron (2020) en un trabajo de reflexión acerca de la educación superior en línea, señala que es un momento que obliga a repensar el sentido de la institución escolar y del currículo formal, de los contenidos disciplinarios alejados de la realidad, de las prácticas docentes hegemónicas y de la gestión académico-administrativa atada a reglamentos obsoletos. "La escuela como la conocemos (desde educación básica hasta superior) deberá cambiar para asumir los retos que planteará a la sociedad que surja de esta contingencia sanitaria, de la inminente crisis económica que posiblemente

\footnotetext{
${ }^{1}$ No se cuenta aún con datos de los principales problemas a los que se enfrentan durante la pandemia, según una encuesta del mismo organismo.
} 
Año 13.

Núm. 34 Tema COVID 19

Especial
Académica sin Frontera

ISSN: 2007-8870

\section{https://revistainvestigacionacademicasinfrontera.unison.mx/index.php/RDIASF}

Recibido el 13 de noviembre de 2020. Dictaminado mediante arbitraje favorablemente 30 de diciembre de 2020.

modifique los procesos productivos de nuestra fábrica global y de la experiencia adquirida de manera forzada en torno al uso de las TIC en educación” (p. 69, paréntesis agregado).

Todos estos elementos afectarán el proceso de enseñanza-aprendizaje, de por sí complejo en condiciones "normales". Al cambio abrupto de la educación presencial a distancia, por ende, sin una planeación y formación adecuada, la UNESCO-IESALC (2020) lo ha llamado educación a distancia de emergencia o coronateaching ${ }^{2}$, porque la mayoría de la planta docente de las instituciones educativas se ha volcado sobre los medios de conectividad digitales para transformar las clases presenciales a modo virtual con carácter emergente. Esto sin que necesariamente se haya modificado el currículum y, mucho menos, las estrategias instruccionales empleadas.

Que el efecto de la pandemia será inmediato, a mediano y largo plazo, también lo señalan Mancera, Serna y Barrios (2020), sin embargo, consideran que a mediano y largo plazo el efecto tendrá que ver con la disponibilidad de recursos tecnológicos y apoyo para su formación a los maestros. Antes de que finalizara el anterior ciclo escolar, los autores aplicaron un cuestionario a 3919 maestros de educación básica de todo el país para conocer su opinión respecto al uso de las TIC. Agruparon los resultados por regiones, por ejemplo, norte, sur, centro (ante las cuales se muestran desigualdades muy notorias). Entre los aspectos a destacar, respecto a las dificultades para desarrollar su trabajo a distancia casi el 50\% de los docentes lo considera muy difícil o difícil. En cuanto a las estrategias de trabajo a distancia predominó la realización de tareas y llenado de libros en forma no digital. Al preguntárseles si empleaban clases virtuales, trabajaban en páginas web específicas y si realizaban videos explicativos, el promedio que señaló que sí, fue menor al diez por ciento, salvo en escuelas privadas, aunque éstas no sobrepasaron el $50 \%$ en ninguna de las tres opciones. Por último, en los tipos de recursos digitales usados para la educación a distancia, el

\footnotetext{
${ }^{2}$ Coronateaching se ha definido como el proceso de "transformar las clases presenciales a modo virtual, pero sin cambiar el curriculum ni la metodología" (p. 26).
} 
Año 13.

Revista de Investigación

Núm. 34 Tema COVID 19

Académica sin Frontera

Especial

ISSN: 2007-8870

https://revistainvestigacionacademicasinfrontera.unison.mx/index.php/RDIASF

Recibido el 13 de noviembre de 2020. Dictaminado mediante arbitraje favorablemente 30 de diciembre de 2020.

más usado resultó ser WhatsApp, seguido por el correo electrónico, debido probablemente, arguyen, a que utilizan un menor consumo de datos. En general, sin dejar de lado las limitaciones de representatividad de la muestra (toda vez que es una encuesta de sondeo y fue respondida solo por profesores interesados), queda la impresión de que, salvo en pocas ocasiones, se llevó una educación a distancia, lo cual debería tenerse en cuenta si se pretende una correcta integración de las TIC que incida en una respuesta no sólo inmediata, sino de largo alcance.

Si bien se reconoce el efecto adverso que pueden tener las condiciones de desigualdad económica (para una revisión detallada ver Chehaibar, 202033), y que se visualiza en la disponibilidad de recursos para poder acceder a la educación virtual (como un televisor, un celular o una computadora con conexión a Internet); la habilitación de los profesores para impartir sus clases en modalidad no tradicional, independientemente del medio por el que pueda acceder a su clase y a los materiales didácticos, no ha evitado una entrada abrupta a una modalidad en la mayoría de los casos desconocida, con requerimientos y curvas de aprendizaje altos que han traído por demás agobio y cansancio en muchos de los casos. Sin mencionar las tensiones ocasionadas por la diversidad de condiciones de aprendizaje y hábitos de estudio, puede decirse también que la implementación de la modalidad a distancia agregó estresores adicionales para las personas durante la contingencia, en específico a padres, estudiantes y maestros.

La emergencia sanitaria, al afectar el proceso de enseñanza presencial, es probable que también afecte el del aprendizaje y este es un asunto pendiente por evaluar. Con todo y las condiciones materiales necesarias de infraestructura con las que pudieran contar los alumnos para

\footnotetext{
${ }^{3}$ En palabras de la autora: "Las posibilidades de trabajo asincrónico entre maestros y estudiantes, el número y tipo de recursos tecnológicos utilizados, o las codiciones para dar marcha a la educación digital hacen evidente las diferencias entre modalidades y tipos educativos, escuelas privadas y escuelas públicas, entre el medio rural y el urbano, entre zonas industrializadas y de mayoría indígena, etcétera. Estas diferencias potencian la exclusión y el rezago educativos, abstaculizan el ejercicio ciudadano de libertad y de la democracia, y mantienen el círculo de la pobreza y la inequidad" (p. 85).
} 
Año 13.

Núm. 34 Tema COVID 19

Especial
Académica sin Frontera

ISSN: 2007-8870

\section{https://revistainvestigacionacademicasinfrontera.unison.mx/index.php/RDIASF}

Recibido el 13 de noviembre de 2020. Dictaminado mediante arbitraje favorablemente 30 de diciembre de 2020.

acceder a la educación no presencial, ellos tampoco contaban con las habilidades para el manejo de la tecnología para situaciones académicas y ajuste a requerimientos de evaluación con elementos tecnológicos.

Sobre el particular, es posible señalar que no es propiamente la disposición de las herramientas digitales (háblese de aplicaciones para acceder a clases vía Internet o tomar la clase transmitida por televisión) el asunto toral, sino la manera de asegurar que se avanza adecuadamente hacia el cumplimiento de los objetivos dispuestos en los planes y programas de estudio. El asunto parece trascender la disponibilidad de la herramienta y el mero uso. Al respecto, Díaz-Barriga (2020) señala que estamos ante una nueva generación de alumnos que está vinculada con la tecnología digital, que la utiliza para comunicarse, sin embargo, no necesariamente puede emplearla como un recurso para el aprendizaje. En breve, no sólo se trata de la discusión acerca de contar o no con la tecnología (TIC), sino la forma de optimizar los recursos de manera que puedan cumplir la función didáctica esperada.

Muchas instituciones educativas han realizado una adaptación pasando de la modalidad presencial a distancia, con una interacción cara a cara mediada por videoconferencia, pero sin realizar una transformación de su docencia (Fardoun, González, Collazos \& Yousef, 2020). Estos autores puntualizan que la modalidad de enseñanza presencial es donde se produce una interacción de enseñanza-aprendizaje cara a cara, mientras que la modalidad de enseñanza a distancia es donde las actividades docentes son no presenciales (que pueden estar basadas en documentos impresos, en videoconferencias y con interacción en línea diferida o directa). No obstante, las ventajas y desventajas de estas modalidades no aseguran o garantizan a priori el aprendizaje de los estudiantes y, en el caso de la educación a distancia, para realizar una transformación real de su enseñanza no sólo deben migrarse los contenidos educativos a un entorno digital, sino tener claro los ajustes necesarios que requieren los programas y planeaciones didácticas al cambiar al entorno digital. 
Año 13.

Núm. 34 Tema COVID 19

Especial
Académica sin Frontera

ISSN: 2007-8870

\section{https://revistainvestigacionacademicasinfrontera.unison.mx/index.php/RDIASF}

Recibido el 13 de noviembre de 2020. Dictaminado mediante arbitraje favorablemente 30 de diciembre de 2020.

En este sentido, Fardoun et al. (2020) realizaron un estudio para explorar las principales dificultades de las instituciones iberoamericanas en este proceso de transformación de emergencia. Aplicaron una encuesta a 102 docentes de educación básica, secundaria y educación superior de países como Argentina (12), Brasil (4), Chile (11), Colombia (16), Costa Rica (3), Ecuador (5), España (7), México (20), Perú (24) durante los meses de abril y mayo de 2020, con el fin conocer sus percepciones sobre los procesos de enseñanza-aprendizaje llevados a cabo durante el confinamiento. Las preguntas fueron las siguientes: 1. ¿Cuál es el mayor problema que ha podido observar en la implementación de modelos de educación virtual en estos momentos de confinamiento?; 2. ¿Qué estrategias pedagógicas ha utilizado para soportar los procesos de enseñanza aprendizaje? 3. ¿Cómo ha sido la interacción? (con estudiantes, colegas y directivos de la institución). En cuanto a la pregunta 1, el mayor problema reportado fue el desconocimiento de los modelos pedagógicos $(27,45 \%)$, seguido por la evaluación del alumnado $(22,55 \%)$ y la falta de plataformas tecnológicas $(19,60 \%)$ junto con la carencia de recursos tecnológicos $(18,63 \%)$; en la pregunta 2, las estrategias y actividades más realizadas fueron los portafolios $(40,01 \%)$, blogs $(29,41 \%)$, foros $(23,53 \%)$ y trabajo colaborativo $(18,63 \%)$. Por último, respecto a la interacción con estudiantes y colegas, se reportó en su mayoría como buena $(50,98 \%)$, regular $(29,41 \%)$ y excelente $(19,60 \%)$.

Se destacan de estos resultados la preocupación de los docentes por seleccionar la mejor forma de enseñar y evaluar, recurriendo a una combinación de estrategias tradicionales pero soportadas por el entorno digital, como lo son el trabajo "colaborativo" y la generación de portafolios, lo cual puede dar la idea de que el maestro, si no está capacitado para desempeñarse en un entorno digital, tiende a desempeñarse en éste como si lo hiciera en un dominio presencial.

Se asume que la educación en línea, diferida o directa, tiene mayor peso o se centra en el estudiante y que el maestro, más que enseñar, pues no da una clase tradicional frente al grupo -idea 
Año 13.

Núm. 34 Tema COVID 19

Especial
Académica sin Frontera

ISSN: 2007-8870

\section{https://revistainvestigacionacademicasinfrontera.unison.mx/index.php/RDIASF}

Recibido el 13 de noviembre de 2020. Dictaminado mediante arbitraje favorablemente 30 de diciembre de 2020.

dominante sobre lo que es enseñar-facilita instrucciones, contenidos y se convierte en un técnico que elige materiales para trabajar con sus alumnos (Díaz-Barriga, 2020). Por el contrario, ni el alumno es su propio maestro, ni el maestro es solamente un supervisor. Como señalan Irigoyen Jiménez y Acuña (2007) cuando analizan las interacciones psicológicas en el ámbito educativo: una interacción didáctica se trata de un intercambio recíproco entre individuos (maestro y estudiante) y los materiales de estudio en condiciones delimitadas por un objetivo instruccional y un ámbito funcional de desempeño (p.e. la física, la química, la biología, la psicología).

Al respecto, Prat y Camerino (2012) y García, Portillo, Romo y Benito (2008) señalan que las tecnologías aplicadas a la enseñanza como recursos didácticos plantean muchos beneficios, pueden llegar a generar entornos innovadores en el sentido de lograr una alfabetización digital pertinente y orientada al auspicio de competencias básicas, para el manejo de la información, su uso interactivo, la búsqueda de información, entre muchos otros. Los autores hacen una distinción entre TIC y TAC (Tecnologías del Aprendizaje y del Conocimiento), enfatizando que las primeras aplicadas a la enseñanza se convierten en TAC, sin embargo, consideramos que el particular no es así de sencillo.

Autores como Carrier (2002) en este mismo sentido señalan que la exploración de las posibilidades de aprendizaje que ofrecen las TIC para los alumnos debe basarse en un análisis crítico de su significación social y cultural. Demasiados productos llamados multimedia sólo son presentaciones apenas renovadas de viejos contenidos. Demasiadas prácticas de clase que pretenden ser modernas son sólo una copia semidisfrazada de viejos métodos. Por lo que advierte: "La eficacia pedagógica no se decreta, aun cuando se juegue mágicamente con los pretendidos poderes de la tecnología. Se construye, lo que implica un trabajo pedagógico específico” (p. 82).

Se alude a una transición entre las TIC y las TAC casi automática por decreto, para enfatizar el uso formativo de las TIC en la práctica educativa, toda vez que se afirma que el modelo TIC 
Año 13.

Núm. 34 Tema COVID 19

Especial
Revista de Investigación

Académica sin Frontera

ISSN: 2007-8870

\section{https://revistainvestigacionacademicasinfrontera.unison.mx/index.php/RDIASF}

Recibido el 13 de noviembre de 2020. Dictaminado mediante arbitraje favorablemente 30 de diciembre de 2020.

resulta excesivamente informático, instrumentalista y poco motivador para aquello que los profesores y estudiantes actuales necesitan, y que requieren aprender a utilizar.

Sin embargo, al no existir un consenso respecto de la definición de las TIC, y sobre todo de como ubicarlas en el contexto de una propuesta de tecnología educativa (Cobo, 2009) se requiere incluir resultados de estudios empíricos acerca de qué y cómo enseñar a través de ellas, del tipo y cualidad funcional de las habilidades y competencias requeridas por parte del del estudiante en los diferentes espacios educativos (sean seminarios, talleres, prácticas, etc.), el tipo de recurso material (materiales de estudio -objetos de aprendizaje, e-books, bibliotecas virtuales, gamificación, videoconferencias, retroalimentación sincrónica y asincrónica, repositorios virtuales, etc.) a ser utilizado en cada unidad de enseñanza-aprendizaje y finalmente, el tipo de criterio a explicitarse como criterio evaluativo. En otras palabras, usar la Tecnología, teniendo claro el qué, el cómo y el para qué ultilizarlas.

Sin embargo, son pocos los estudios que reportan el uso efectivo de las TIC en el proceso de enseñanza-aprendizaje, la mayoría de ellos se centran en la percepción que tienen tanto docentes, como estudiantes en relación con sus competencias digitales y a su uso en ambientes académicos. Por ejemplo, Zempoalterca, Barragán, González y Guzmán (2017) a partir de una técnica de encuesta analizaron la percepción que tienen docentes y estudiantes en cuanto a su formación en TIC en ambientes Web 1.0 y 2.04. Participaron en el estudio 5775 estudiantes y 334 docentes de cinco instituciones públicas que imparten carreras del área de ciencias administrativas de la zona centro del País. Las variables analizadas fueron la percepción que tienen docentes y estudiantes acerca de sus competencias digitales. Para el caso de los docentes se analizó su antigüedad,

\footnotetext{
${ }^{4}$ El término web es definido como un ambiente de desarrollo y ejecución de programas o servicios a través de una forma de interfaz gráfica para usuarios. La Web 1.0 expone información de manera unidireccional, lo cual no permite la interacción ni aportaciones instantáneas de los usuarios, o en la Web 2.0 está basada en el intercambio y la aportación bidireccional que se puede dar entre (profesores) diseñadores y usuarios.
} 
Año 13.

Núm. 34 Tema COVID 19

Especial
Académica sin Frontera

ISSN: 2007-8870

\section{https://revistainvestigacionacademicasinfrontera.unison.mx/index.php/RDIASF}

Recibido el 13 de noviembre de 2020. Dictaminado mediante arbitraje favorablemente 30 de diciembre de 2020.

formación en TIC, percepción de acceso, y disponibilidad de TIC en la institución, así como uso de las TIC en actividades docentes con ambientes Web 1.0 y 2.0; para los estudiantes se recuperó el promedio del periodo escolar, nivel de estudios, percepción de formación en TIC, uso de internet en actividades académicas y tareas asignadas por los docentes. Los resultados mostraron que existe una relación de la competencia digital en cuanto a la formación en TIC, así como un vínculo directo de su uso entre docentes y estudiantes. Un dado adicional importante, es que existe una alta correlación entre la proporción de docentes que utilizan la Web 2.0 y el número de estudiantes que también dicen utilizarlas.

Por su parte, Tirado y Roque (2018) llevaron un estudio para determinar la frecuencia de uso y función que estudiantes de una universidad pública mexicana dan a las TIC en los contextos educativos. Participaron 309 estudiantes de manera voluntaria, a los cuales se les aplicó una escala tipo Likert conformada por 46 reactivos. Los resultados indicaron que los estudiantes principalmente utilizan las TIC en contextos informales con fines recreativos, de manera que sólo observan, escuchan o leen contenidos no vinculados a cuestiones académicas. Los autores sugieren que el uso de las TIC en la educación superior debe promoverse con planes de acción que adapten las habilidades informales de los universitarios y a competencias tecnológicas pertinentes a la educación formal.

Otros autores como Segura y Escudero (2019) realizaron un estudio con el propósito de analizar la apreciación estudiantil en torno al e-Learning curricular. A partir de un cuestionario describieron la percepción y satisfacción de los estudiantes con relación a materias en línea, esto con el propósito de determinar las problemáticas que inciden negativamente en el proceso de enseñanza-aprendizaje virtual. Con un Cuestionario de Apreciación Estudiantil (CAE) encuestaron a 1224 estudiantes de diferentes facultades (sociales, administrativas, ingenierías, idiomas, entre otras) que cursaban al menos una asignatura en línea. Los resultados señalaron una falta de claridad 
Año 13.

Núm. 34 Tema COVID 19

Especial
Académica sin Frontera

ISSN: 2007-8870

\section{https://revistainvestigacionacademicasinfrontera.unison.mx/index.php/RDIASF}

Recibido el 13 de noviembre de 2020. Dictaminado mediante arbitraje favorablemente 30 de diciembre de 2020.

en la comunicación con los tutores, escaso seguimiento académico vinculado a la retroalimentación, así como poca claridad en la comunicación por parte de los profesores. Estos resultados son discutidos en términos de las problemáticas que pueden surgir en la aplicación de una metodología de diseño instruccional para ambientes virtuales. Los autores enfatizan que la educación a través de medios digitales implica el desarrollo de habilidades básicas relacionadas con la comunicación, a saber: ortografía, redacción, semántica, lectura, escucha, oratoria y comprensión. Las modalidades educativas virtuales se basan predominantemente en medios asíncronos, por lo que la falta de comprensión entre profesor (tutor) y estudiante puede darse por una carencia de habilidades de lecto-escritura.

También en un contexto mexicano Chávez y Gutiérrez (2015) llevaron a cabo un estudio para determinar el uso que hacen los estudiantes de las redes sociales en clase como facilitadoras de su aprendizaje; para este propósito entrevistaron a 140 universitarios de un Estado del Norte del País, encontrando que 99\% de ellos utilizó una o varias redes sociales (WhatsApp, 100\% y Facebook, 80\%) a través de sus teléfonos móviles para compartir información de sus trabajos, explicar todos los temas de clases y, además, un distractor para el desempeño académico. Se llevó a cabo un estudio exploratorio, a partir de un cuestionario de quince preguntas cerradas en cuanto al uso de las redes sociales dentro y fuera del salón de clase, su interacción con otras personas, su uso académico y la percepción de seguridad respecto a los temas adquirida por parte de los alumnos. Sin embargo, los autores no analizaron si estas redes sociales son, al mismo tiempo, un posible distractor para el desempeño académico.

Si bien estos estudios nos brindan información descriptiva acerca de la percepción del uso de las TIC, se requiere adicionalmente se analicen las variables que configuran un episodio de interacción didáctica mediado a través de las TIC, sea de tipo sincrónico o asíncronico. 
Año 13.

Académica sin Frontera

Núm. 34 Tema COVID 19

Especial

ISSN: 2007-8870

https://revistainvestigacionacademicasinfrontera.unison.mx/index.php/RDIASF

Recibido el 13 de noviembre de 2020. Dictaminado mediante arbitraje favorablemente 30 de diciembre de 2020.

Desde una aproximación psicológica al análisis del proceso educativo, se torna relevante la caracterización de las condiciones (idóneas) para el cumplimiento de los distintos criterios de logro a lo largo de las trayectorias escolares. Es decir, cómo los desempeños del profesor y del estudiante se van encaminando tanto morfológica como funcionalmente al cumplimiento de los objetivos curriculares en cada uno de los espacios educativos. En este sentido, la habilitación del profesor y del estudiante en el manejo de herramientas digitales resulta ser una pieza fundamental, que no implica solamente el dominio de técnicas instrumentales (p.e. uso de aplicaciones como Power Point, correo electrónico, redes sociales como Facebook y WhatsApp, entre otros).

Así, la relación entre Psicología y Educación se presenta como un enfoque interdisciplinario con el propósito de brindar una lógica conceptual y operacional del proceso de enseñanza y aprendizaje mediado a través de las TIC.

\section{Algunas aportaciones de la psicología al ámbito de la educación: el análisis de las interacciones didácticas mediadas a través de las TIC}

A partir de lo anterior, hablar de TIC no es necesariamente equivalente a hablar de Tecnología Educativa. La Tecnología Educativa en este manuscrito es entendida como aquel conocimiento científico derivado de estudios de investigación básica o aplicada que ha sido sistematizado a través de modelos de interfaz para el análisis de los procesos educativos (para una revisión exhaustiva de cada uno de ellos ver Ibáñez y Ribes, 2001; Irigoyen, Jiménez y Acuña, 2004, 2007; León, Morales, Silva y Carpio, 2011; Morales, Alemán, Canales, Arroyo y Carpio, 2013). Siendo los factores que configuran un episodio de interacción didáctica, los siguientes: 1) el ámbito funcional de desempeño (científico, tecnológico, docente); 2) los objetivos instruccionales o de aprendizaje; 3 ) el desempeño docente; 4) el desempeño del estudiante o estudiantil; y, 6) los materiales de estudio (u objetos referentes). 
Año 13.

Núm. 34 Tema COVID 19

Especial
Académica sin Frontera

ISSN: 2007-8870

\section{https://revistainvestigacionacademicasinfrontera.unison.mx/index.php/RDIASF}

Recibido el 13 de noviembre de 2020. Dictaminado mediante arbitraje favorablemente 30 de diciembre de 2020.

La teoría que da sustento a esta propuesta psicopedagógica es la Psicología Interconductual, entendida como una ciencia funcional del comportamiento que puede aportar al campo de la educación como una interdisciplina, dicha teoría parte de la concepción de que las interacciones psicológicas se explican como campos de interdependencia funcional en las que puede participar docente-estudiante-material de estudio, estudiante-material de estudio, docente-material de estudio, y otras variables del entorno que pueden afectar o facilitar una forma de interacción particular como son, el tipo de criterio de logro y su nivel funcional.

Una verdadera propuesta de tecnología educativa debe provenir de una teoría general de proceso psicológico (como marco de teoría general del comportamiento), que permita delinear qué se enseña y cómo, qué se aprende y cómo, y criterios de evaluación utilizar para la caracterización de los desempeños ante los objetivos curriculares y didácticos, permitiendo así, analizar tanto los cambios morfológicos como funcionales ante las distintas situaciones problema por resolver. El análisis psicológico de la educación formalizada requiere contar con un marco teórico armonioso y con categorías apropiadas para dar cuenta de modulaciones de comportamiento que acontecen en el proceso de enseñanza-aprendizaje, sea en modalidad presencial o virtual.

En general, la discusión versa alrededor del desarrollo de dos caminos paralelos, pero independientes que han impedido -a nuestro juicio- la construcción de una verdadera Tecnología Educativa: el educativo y el tecnológico. Basicamente, la noción de tecnología educativa se ha equiparado con el concepto de interacción-medios. Nayiv (2020) señala que el tecnólogo educativo se encuentra en la posición de dimensionar mutuamente estos dos ámbitos: el educativo y el tecnológico, y que el éxito de esta incursión requiere de la conjugación interdisciplinaria de todos los expertos involucrados. En palabras del autor: "En esta dirección, la función de los profesionales de la educación es participar en este avance tecnológico, originar y aportar las teorías que expliquen los procesos de cognición y la investigación de procesos de enseñanza-aprendizaje y diseño de 
Año 13.

Núm. 34 Tema COVID 19

Especial
Académica sin Frontera

ISSN: 2007-8870

\section{https://revistainvestigacionacademicasinfrontera.unison.mx/index.php/RDIASF}

Recibido el 13 de noviembre de 2020. Dictaminado mediante arbitraje favorablemente 30 de diciembre de 2020.

contenidos y que informen y formalicen el desarrollo técnico del diseño de interfaces educativas altamente tecnológicas, que corresponde a los profesionales de tecnología" (p. 162).

Nayiv (2020) en un análisis histórico llevado a cabo retomando autores como Moore (1989), Anderson (2003), Akyl \& Garrison (2013), Jia (2020), plantea que la propuesta de clasificación para entender la mediación en los procesos formativos a distancia ha incluido tres tipos de relaciones: la interacción estudiante-contenido (learner-content interaction); la interacción estudiante-instructor (learner-instructor interaction) y la interacción estudiante-par (learner-learner interaction); pero no la relación estudiante-interfaz como una posible manera dar cuenta de la interacción referida a los dispositivos digitales. Sobre todo el autor señala que la ausencia de la interacción aprendiz-interfaz en los modelos teóricos podría interpretarse de múltiples formas; pero que denota un vacío conceptual en el funcionamiento de la interfaz como medio tecnológico y cimiento de la formación tecnológicamente mediada.

De tal manera que se requiere conocer las condiciones materiales y funcionales que probabilizan el uso de la tecnología como un recurso al servicio de la planificación e implementación del proceso de enseñanza-aprendizaje. Es decir, la primera vinculada a la disponibilidad de recursos digitales en las universidades, y la segunda, referida a la habilitación de los docentes y alumnos para un uso eficaz.

Así, la mediación entendida como el elemento que constituye un factor funcional que configura una situación de enseñanza-aprendizaje, basada en la noción de interacción didáctica a través de las TIC, deberá considerar cuando menos los siguientes aspectos:

Claridad instruccional (qué y cómo se va a planear). La planeación didáctica describe la organización del conjunto de actividades que constituyen las prácticas identificadas a partir de los distintos ámbitos funcionales de desempeño, a saber, la práctica científica, tecnológica y docente (Carpio, Pacheco, Canales y Flores, 1998; Acuña, Irigoyen, Jiménez, Ramírez y Dávila, 2019). 
Año 13.

Núm. 34 Tema COVID 19

Especial
Académica sin Frontera

ISSN: 2007-8870

\section{https://revistainvestigacionacademicasinfrontera.unison.mx/index.php/RDIASF}

Recibido el 13 de noviembre de 2020. Dictaminado mediante arbitraje favorablemente 30 de diciembre de 2020.

Cada dominio de conocimiento hace referencia a la caracterización de un objeto de estudio, un nivel de análisis y una metodología particular que le permite segmentar y estudiar la naturaleza de manera congruente. Aun dentro de cada dominio de conocimiento, es posible caracterizar un conjunto de haceres y decires como prácticas filosóficas, teóricas, tecnológicas, profesionales, transdisciplinares (Reyna y Hernández, 2017). Los autores lo circunscriben al análisis de la Psicología, pero bien puede aplicarse a otros ámbitos o dominios científicos.

Así, el conjunto de actividades dentro de dichas prácticas delimitará la pertinencia de la planeación e implementación de las interacciones didácticas, en otras palabras, el quehacer tanto del profesor como del estudiante deberá corresponderse con los objetivos de aprendizaje, prescritos por un curriculum, sea una interacción sincrónica o no, toda vez que la interacción didáctica es definida en términos funcionales y no como una relación con temporalidad y situacionalidad específica.

Sabemos que la modalidad virtual requiere de un diseño preciso de lo que se tiene que llevar a cabo y cómo. De tal manera que la planeación didáctica deberá explicitar el qué, el cómo y el para qué en términos de la organización de los saberes (contenidos), secuencia y orden en las actividades programadas, formas de comunicación e integración de los contenidos, y complejidad de los criterios de evaluación que incluya elementos y sus variaciones (sea en cualquiera de los niveles de educación formal); estos elementos deberán ser considerados en el uso de las diferentes plataformas educativas que combinan modelos de LCMS (Learning Content Management System), LMS (Learning Management System) o EVA (Entorno Virtual de Aprendizaje), por ejemplo: Schoology, CourseSite by Blackboard, Moodle, Teachstars, por mencionar algunos.

Explicitación de criterios considerando el tipo de tarea y su nivel de complejidad. Las tareas y criterios a cumplirse deben asignarse exclusivamente en función de lo que se quiere que el alumno aprenda. Una tarea puede clasificarse en términos de su forma (o morfología); si el 
Año 13.

Núm. 34 Tema COVID 19

Especial
Académica sin Frontera

ISSN: 2007-8870

\section{https://revistainvestigacionacademicasinfrontera.unison.mx/index.php/RDIASF}

Recibido el 13 de noviembre de 2020. Dictaminado mediante arbitraje favorablemente 30 de diciembre de 2020.

estudiante tiene que nominar, describir, relacionar o diagramar, formular, etcétera, o en términos de una complejidad funcional diferenciada que puede incluir desde interacciones intrasituacionales, extrasituacionales hasta transituacionales (Varela y Quintana, 1995). El uso de materiales diversos en modalidad -visual, textual, textual-ilustrada, videos o conferencias- deberán ser variados, pero es importante se determine de manera clara el o los desempeños a ser exhibidos; las demandas pueden implicar lo que desde esta aproximación teórica se ha analizado como modos lingüísticos (observar, escuchar, leer, escribir, hablar) Tamayo (2014), en función de pertinencia con lo que se desea conseguir como desempeño adecuado, evitando así, solicitar la ejecución de tareas que solo gasten tiempo y recursos sin que incidan positivamente en lo que se busca que aprenda el estudiante (p.e. observar y escuchar).

Finalmente, la variedad de situaciones de evaluación del y para el aprendizaje dependerá de los objetivos de aprendizaje (Sánchez y Martínez, 2020), del nivel de complejidad en el que se desea sea exhibido el desempeño del estudiante, que puede ir desde menor a mayor complejización, por ejemplo, que es menos complejo transcribir un texto que hacer un resumen, por mencionar alguno. Otro aspecto importante para considerar es que las habilidades y competencias tanto académicas como tecnológicas son diferenciadas dependiendo de las historias escolares, y no necesariamente están asociadas a un nivel escolar. Un estudiante de bachillerato puede estar más habilitado en el uso de la tecnología que un estudiante universitario. Por ello, deberá atenderse a la exploración competencial (Silva et al, 2014) como evaluación de las precurrentes necesarias en cada uno de los espacios educativos, además no podemos pasar por alto que cada alumno aprende a su propio ritmo y, por lo tanto, la planeación y diseño de las plataformas web deberá considerar "rutas" diversas para lograr el mismo fin o los mismos fines, pero dando alternativas variadas para que cada estudiante (o usuario) aprenda a su propio ritmo. 
Año 13.

Núm. 34 Tema COVID 19

Especial
Académica sin Frontera

ISSN: 2007-8870

\section{https://revistainvestigacionacademicasinfrontera.unison.mx/index.php/RDIASF}

Recibido el 13 de noviembre de 2020. Dictaminado mediante arbitraje favorablemente 30 de diciembre de 2020.

Retroalimentación. Consiste en la información proporcionada a una persona acerca de su desempeño, la cual refuerza las respuestas correctas y aumenta la probabilidad de que se repita si es retroalimentada como correcta (Guerrero y Ortiz, 2007; Crone-Todd et al., 2007). Ahora que se critica que la enseñanza, aún en estas condiciones, sólo busca cumplir el currículo formal y calificar (Díaz-Barriga, 2020) o bien que no se cuentan con mecanismos apropiados, que permitan tener certeza de la veracidad de las respuestas de los estudiantes en estas condiciones (Fardoun et al., 2020), esta puede ser una forma de asegurar, más allá de puntajes, que se emitan los comportamientos deseados para alcanzar un objetivo o meta.

Las distintas plataformas disponen de condiciones distintas para la retroalimentación, algunas la posibilitan de manera sincrónica, otras de manera diferida. Qué tipo de información se le presenta al estudiante (o usuario) y en qué cualidad, son aspectos que han sido investigados desde el análisis de proceso básico (Irigoyen et al., 2002), pero que requiere analizarse en términos de condiciones "reales" de interacción didáctica en las distintas plataformas web.

\section{Conclusión}

Al parecer, el cambio de modalidad en el proceso de enseñanza-aprendizaje no ha sido recibido muy positivamente. Parte de la desafección proviene de que el contenido que se ofrece nunca fue diseñado en el campo de un curso de educación superior (y niveles previos) a distancia, sino que intenta paliar la ausencia de clases presenciales con clases virtuales sin mayor preparación previa. Sin embargo, al no haber tiempo suficiente para la transición por la Pandemia de COVID-19, el profesorado se ha visto desafiado a ubicar soluciones "creativas", ajustándose sobre la marcha, implicándose una "flexibilización" de los contenidos y diseños de los cursos para medio cubrir con los objetivos de aprendizaje planteados con antelación. 
Año 13.

Núm. 34 Tema COVID 19

Especial
Académica sin Frontera

ISSN: 2007-8870

\section{https://revistainvestigacionacademicasinfrontera.unison.mx/index.php/RDIASF}

Recibido el 13 de noviembre de 2020. Dictaminado mediante arbitraje favorablemente 30 de diciembre de 2020.

El estudiante, por su parte, ha tenido que adecuarse a requerimientos para los que no estaba habilitado y, por ende, solo los ha podido solventar de manera parcial. Los jóvenes que llegan a la universidad no llegan bien preparados, no hay un dominio de habilidades de lectura y escritura científica, ni tampoco la utilización de los medios digitales con propósitos académicos; lo cual en el caso de la pandemia se quedó en un segundo plano. Un aspecto importante a tomar en cuenta por parte del alumnado es que la expectativa es distinta si desde un principio ingresó a una licenciatura o un curso en línea. Con todos los elementos sociales que acompañan siempre la experiencia presencial en una IES (institución de educación superior), la historia previa de interacción con ambientes virtuales es un factor importante, dado que estos ambientes requieren que los alumnos sepan autorregularse en varios aspectos, cuando menos, por ejemplo, dosificar sus tiempos, programar sus actividades y lecturas en horarios definidos, entre otros. En este sentido, De la Cruz (2020) comenta al respecto: "La tensión es evidente, no los hemos formado para la autorregulación y ahora se les exige asumir responsabilidades y un papel activo, cuando estos procesos se aprenden y requieren de andamios que contribuyan a la autonomía y al pensamiento crítico" (De la Cruz, 2020, p. 45).

Esto sin duda pone de manifiesto nuevos y grandes retos para la educación superior, implicará la revisión y verdadera flexibilización de los planes y programas de estudio, las condiciones del desarrollo de saberes, haceres, prácticas, iniciarán transformaciones que van a requerir salidas profesionales abiertas y cambiantes en los nuevos empleos, que se darán en contextos móviles y de inestabilidad.

La situación de emergencia forzó un cambio en la modalidad del proceso de enseñanzaaprendizaje y demostró que no estábamos preparados ni en disponibilidad de condiciones materiales (institucionales educativas ni familiares) ni de habilitación suficiente de los profesores y estudiantes, pero tampoco en los aspectos de administración y gestión educativa. Debe 
Año 13.

Núm. 34 Tema COVID 19

Especial
Académica sin Frontera

ISSN: 2007-8870

\section{https://revistainvestigacionacademicasinfrontera.unison.mx/index.php/RDIASF}

Recibido el 13 de noviembre de 2020. Dictaminado mediante arbitraje favorablemente 30 de diciembre de 2020.

reconocerse que esta emergencia representa una oportunidad para iniciar cambios sustanciales en la concepción misma de la planeación educativa, del proceso de enseñanza-aprendizaje mediado a través de las TIC. Un cambio hacia una educación que no sólo busque salvar el año escolar, cumplir el currículo formal y calificar a los estudiantes, sino cumplir la meta que en un comienzo se puso la educación: vincular la realidad a la escuela (Díaz-Barriga, 2020). En palabras de Plá (2020), pasar de la estructura pesada y autoritaria sostenida por funcionarios como por algunos docentes y, en lugar de imponer la escuela, preguntarse cómo ofrecer apoyo en esta crisis sanitaria a la población que atiende, en breve, en lugar de que la escuela ponga a las familias a su servicio, que la escuela se ponga al servicio de la sociedad y su coyuntura. Esto también debería formar parte del proceso de enseñanza-aprendizaje.

Por último, en la agenda de la UNESCO desde el año 2014 hay un asunto pendiente, acotar la brecha entre las expectativas y manejo de la tecnología entre jóvenes y la posibilidad de acceder a ella, tanto en la universidad como en cualquier otro lugar. Los asuntos que quedan aplazados son: la alfabetización digital; la educación universal; el acceso a recursos educativos sin importar la ubicación del estudiante, ampliar la oferta formativa más allá de los centros escolares, crear situaciones flexibles para el aprendizaje autorregulado, eliminar barreras espaciales y temporales entre profesores y estudiantes; fomentar la interacción y la comunicación entre los estudiantes o usuarios y facilitar una formación permanente.

\section{Referencias}

Acuña, K.F., Irigoyen, J.J. y Jiménez, M., Ramírez, D. y Dávila, J. (2019). ¿Qué aprenden los estudiantes de estudiantes de Psicología de pregrado?: un estudio de caso. En I. Zepeda, F. Cabrera, J. Camacho y E. Camacho. Aproximaciones al estudio del Comportamiento y sus Aplicaciones (pp. 416-436). Guadalajara: Universidad de Guadalajara. 
Año 13.

Académica sin Frontera

Núm. 34 Tema COVID 19

Especial

ISSN: 2007-8870

https://revistainvestigacionacademicasinfrontera.unison.mx/index.php/RDIASF

Recibido el 13 de noviembre de 2020. Dictaminado mediante arbitraje favorablemente 30 de diciembre de 2020.

Barrón, M.C. (2020). La educación en línea transiciones y disrupciones. En IISUE. Educación y pandemia. Una visión académica (pp. 66-74). México: UNAM. Recuperado de https://www.iisue.unam.mx/nosotros/covid/educacion-y-pandemia

Brooks, S., Webster, R., Smith, L., Woodland, L., Wessely, S., Greenberg, N. \& Rubin, G. (2020). The psychological impact of quarantine and how to reduce it: rapid review of the evidence. The Lancet. 95, 912-20. https://doi.org/10.1016/ S0140-6736(20)304608

Carrier, J. (2002). Escuela y multimedia. México: Siglo XXI.

Carpio, C., Pacheco, V., Canales, C. y Flores, C. (1998). Comportamiento inteligente y juegos de lenguaje en la enseñanza de la psicología. Acta Comportamentalia, 6(1), 47-60. Recuperado de http://www.revistas.unam.mx/index.php/acom/article/view/18244

Chávez, I. y Gutiérrez, M. (2015). Redes sociales como facilitadoras del aprendizaje de ciencias exactas en la educación superior. Apertura, Revista de Innovación Educativa, 7(2), 1-12. Recuperado de http://www.scielo.org.mx/pdf/apertura/v7n2/2007-1094apertura-7-02-00049.pdf

Chehaibar, L. (2020). Flexibilidad curricular. Tensiones en tiempos de pandemia (pp. 83-91). México: Universidad Nacional Autónoma de México. Recuperado de https://www.iisue.unam.mx/nosotros/covid/educacion-y-pandemia

Crone-Todd, D., Eyre, H., Hutchens, S., Jones, J. \& Pear, J. (2007). The effect of changing grading criteria on student writing. The Behavior Analyst Today, 8, 35-42.

Cobo, J. (2009). El concepto de tecnologías de la información. Benchmarking sobre las definiciones de las TIC en la sociedad del conocimiento. Zer. Revista de Estudio de Comunicación, $\quad$ 14(27), 295-318. Recuperado de https://ojs.ehu.eus/index.php/Zer/article/view/2636/2184 
Año 13.

Académica sin Frontera

Núm. 34 Tema COVID 19

Especial

ISSN: 2007-8870

https://revistainvestigacionacademicasinfrontera.unison.mx/index.php/RDIASF

Recibido el 13 de noviembre de 2020. Dictaminado mediante arbitraje favorablemente 30 de diciembre de 2020.

De la Cruz, G. (2020). El hogar y la escuela: lógicas en tensión ante la COVID-19. En IISUE. Educación y pandemia. Una visión académica (pp. 39-46). México: Universidad Nacional Autónoma de México. Recuperado de https://www.iisue.unam.mx/nosotros/covid/educacion-y-pandemia

Díaz-Barriga, A. (2020). La escuela ausente, la necesidad de replantear su significado. En IISUE. Educación y pandemia. Una visión académica (pp. 19-29). México: Universidad Nacional Autónoma de México. Recuperado de https://www.iisue.unam.mx/nosotros/covid/educacion-y-pandemia

Fardoun, H., González, C., Collazos, C. y Yousef, M. (2020). Estudio exploratorio en Iberoamérica sobre procesos de enseñanza-aprendizaje y propuesta de evaluación en tiempos de pandemia. Education in the Knowledge Society, 21, 17, 1-9. https://doi.org/10.14201/eks.23437

García, F., Portillo, J., Romo. y Benito, M. (2008). Nativos digitales y modelos de aprendizaje. Universidad de País Vasco. Recuperado en http://spdece07.ehu.es/actas/García.pdf

Guerrero, A. y Ortiz, G. (2007). El papel de la retroalimentación y la ausencia o presencia de instrucciones en la elaboración de descripciones en tareas de discriminación condicional. Acta Colombiana de Psicología, 10, 1, 5-13. Recuperado de https://www.redalyc.org/pdf/798/79810102.pdf

Ibáñez, C. y Ribes, E. (2001). Un análisis interconductual de los procesos educativos. Revista Mexicana de Psicología, 18(3), 359-371.

Irigoyen, J.J., Carpio, C., Jiménez, M., Silva, H., Acuña, K.F. y Arroyo, A. (2002). Efectos de los diferentes tipos funcionales de retroalimentación y su presentación parcial en el entrenamiento y transferencia de desempeños efectivos. Revista Sonorense de Psicología, 16, 1 y 2, 23-31. 
Año 13.

Académica sin Frontera

Núm. 34 Tema COVID 19

Especial

ISSN: 2007-8870

https://revistainvestigacionacademicasinfrontera.unison.mx/index.php/RDIASF

Recibido el 13 de noviembre de 2020. Dictaminado mediante arbitraje favorablemente 30 de diciembre de 2020.

Irigoyen, J.J., Jiménez, M. y Acuña, K. (2004). Evaluación competencial del aprendizaje. En J.J. Irigoyen y M. Jiménez (Coords.), Análisis funcional del comportamiento y educación (pp. 77-106). Hermosillo: Universidad de Sonora.

Irigoyen, J.J., Jiménez, M. y Acuña, K. (2007). Aproximación a la pedagogía de la ciencia. En J.J. Irigoyen, M. Jiménez y K.F. Acuña. Enseñanza, Aprendizaje y Evaluación. Una aproximación a la Pedagogía de las Ciencias (pp. 13-44). Hermosillo: Universidad de Sonora.

León, A., Morales, G., Silva, H. y Carpio, C. (2011). Análisis y evaluación del comportamiento docente en el nivel educativo superior. En V. Pacheco y C. Carpio (Coords.), Análisis del Comportamiento. Observación y Métricas (pp. 79-99). México: Universidad Nacional Autónoma de México.

Mancera, C., Serna, L. y Barrios, M. (2020). Pandemia: maestros, tecnología y desigualdad. Nexos. Recuperado de https://educacion.nexos.com.mx/?p=2286

Morales, G., Alemán, M., Canales, C., Arroyo, R. y Carpio, C. (2013). Las modalidades de las interacciones didácticas: entre los disensos esperados y las precisiones necesarias. Conductual, Revista Internacional de Interconductismo y Análisis de la conducta, 1(2), 73-89. Recuperado de https://www.conductual.com/articulos/Las\%20modalidades\%20de\%20las\%20inter acciones\%20didacticas.pdf

Nayiv, A. (2020). El futuro de la interacción aprendiz-interfaz, una visión desde la tecnología educativa. Apertura, 12,(2), 150-165. http://dx.doi.org/10.32870/Ap.v12n2.1910

Organización de las Naciones Unidas para la Educación, la Ciencia y la Cultura \& Instituto Internacional para la Educación Superior en América y el Caribe (UNESCO IESALC). (2020). COVID-19 y educación superior: De los efectos inmediatos al 
"Fl silwer ile mis hijics

Año 13.

Núm. 34 Tema COVID 19

Especial

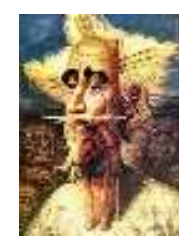

Revista de Investigación

Académica sin Frontera

ISSN: 2007-8870

\section{https://revistainvestigacionacademicasinfrontera.unison.mx/index.php/RDIASF}

Recibido el 13 de noviembre de 2020. Dictaminado mediante arbitraje favorablemente 30 de diciembre de 2020.

día después. Análisis de impactos, respuestas políticas y recomendaciones. Recuperado de http://www.iesalc.unesco.org/wpcontent/uploads/2020/05/COVID-19-ES-130520.pdf

Ortiz, G. y Cruz, Y. (2011). El papel de la precisión instruccional y la retroalimentación en la ejecución y las descripciones poscontacto. Revista Mexicana de Análisis de la Conducta, 37, 1, 69-87. https://doi.org/10.5514/rmac.v37.i1.24740

Plá, S. (2020). La pandemia en la escuela: entre la opresión y la esperanza. En IISUE. Educación y pandemia. Una visión académica (pp. 30-38). México: Universidad Nacional Autónoma de México. Recuperado de https://www.iisue.unam.mx/nosotros/covid/educacion-y-pandemia

Prat, Q. y Camerino, F. (2012). Las tecnologías del aprendizaje y el conocimiento (TAC) en la educación física, la WebQuest como recurso didáctico. Apunts. Educación Física y Deportes, 109(3), 44-53. doi: 10.5672/apunts.2014-0983.es.(2012/3.109.04

Reyna, W. y Hernández, M. (2017). Enseñanza-aprendizaje de la psicología: reflexiones desde la matriz cienfica interconductual. Interacciones, 3(3), 171-182. doi: 10.24016/2017.v3n3.67

Sánchez, M. y Martínez, A. (2020). Evaluación de y para el aprendizaje: instrumentos y estrategias. México: Universidad Nacional Autónoma de México.

Segura, C. y Escudero, A. (2019). Análisis de la apreciación de estudiantes de materias en línea: el caso de una institución mexicana de educación superior. Revista de Educación y Desarrollo, 50, julio-septiembre, 73-83. Recuperado de http://www.cucs.udg.mx/revistas/edu_desarrollo/anteriores/50/50_Segura.pdf

Shigemura, J., Ursano, R., Morganstein, J., Kurosawa, M. \& Benedek, D. (2020). Public responses to the novel 2019 coronavirus (2019-nCoV) in Japan: Mental health consequences 
Año 13.

Revista de Investigación

Núm. 34 Tema COVID 19

Académica sin Frontera

Especial

ISSN: 2007-8870

https://revistainvestigacionacademicasinfrontera.unison.mx/index.php/RDIASF

Recibido el 13 de noviembre de 2020. Dictaminado mediante arbitraje favorablemente 30 de diciembre de 2020.

and target populations. Psychiatry and Clinical Neurosciences 74, 277-283. doi:10.1111/pcn.12988

Silva, H., Morales, G., Pacheco, V., Camacho, A., Garduño, H. y Carpio, C. (2014). Didáctica como conducta: una propuesta para la descripción de las habilidades de enseñanza. Revista Mexicana de Análisis de la Conducta, 40 (3), 32-46. Recuperado de http://rmac-mx.org/wp-content/uploads/2015/03/03_RMAC_40_3.pdf

Tamayo, J. (2014). La investigación en modos lingüísticos: una breve mirada retrospectiva y un ejercicio de clasificación. En G. Mendoza, M. Reyes y P. Barrera (Coords.) Algunas aportaciones psicológicas y sociológicas a la educación (pp. 81-107). Chihuahua: Universidad Autónoma de Chihuahua.

Tirado, P. y Roque, M. (2018). TIC y contextos educativos: frecuencia de uso y función por universitarios. EDUTEC, Revista Electrónica de Tecnología Educativa, 67(marzo), 31-47. doi: https://doi.org/10.21556/edutec.2019.67.1135

Torales, J., O’Higgins, M., Castaldelli-Maia, J. \& Ventriglio, A. (2020). The outbreak of COVID19 coronavirus and its impact on global mental health. International Journal of Social Psychiatry 1-4. doi: 10.1177/0020764020915212

Varela, J. y Quintana, C. (1995). Comportamiento inteligente y su transferencia. Revista Mexicana de Análisis de la Conducta, 21(1), 47-66.

Zempoalterca, B., Barragán, J., González, J. y Guzmán, T. (2017). Formación en TIC y competencia digital en la docencia en instituciones públicas de educación superior. $\begin{array}{llll}\text { Apertura, } & 9(1), & \text { 80-96. } & \text { Recuperado }\end{array}$ http://www.scielo.org.mx/pdf/apertura/v9n1/2007-1094-apertura-9-01-00080.pdf 
Año 13.

Núm. 34 Tema COVID 19

Especial

https://revis
Académica sin Frontera

ISSN: 2007-8870

Recibido el 13 de noviembre de 2020. Dictaminado mediante arbitraje favorablemente 30 de diciembre de 2020.

\section{Directorio Institucional}

Dr. Enrique Fernando Velázquez Contreras

Rector

Dr. Ramón Enrique Robles Zepeda

Secretario General Académico

Dra. Rosa María Montesinos Cisneros

Secretaria General Administrativa

Dr. Rodolfo Basurto Álvarez

Director de Vinculación y Difusión

Dra. Adriana Leticia Navarro Verdugo

Vicerrectora de la Unidad Regional Sur

Dr. Ernesto Clark Valenzuela

Director de la División de Ciencias Económicas y Sociales

Dr. Francisco Espinoza Morales

Secretario de la División de Ciencias Económico y Sociales

Dra. Leticia María González Velásquez

Jefe del Departamento de Ciencias Económico Administrativas

Dra. Lidia Amalia Zallas Esquer

Jefe de Departamento de Ciencias Sociales 

"Fl sober ile mis hijos
hardi mi gronderis"

Año 13.

Núm. 34 Tema COVID 19

Especial

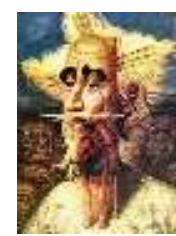

Revista de Investigación

Académica sin Frontera

ISSN: 2007-8870

https://revistainvestigacionacademicasinfrontera.unison.mx/index.php/RDIASF

Recibido el 13 de noviembre de 2020. Dictaminado mediante arbitraje favorablemente 30 de diciembre de 2020.

\section{Comité Directivo}

\section{Editor Responsable}

Dr. Francisco Espinoza Morales

Universidad de Sonora

Directora

Dra. Leticia María González Velásquez

Universidad de Sonora

\section{Subdirector}

Dr. Javier Carreón Guillen

Universidad Nacional Autónoma de México

Editor Científico

Dr. Cruz García Lirios

Universidad Autónoma del estado de México

Master Gráfico

M.T.I. Francisco Alan Espinoza Zallas

Universidad Estatal de Sonora

Nos complace anunciar que su diario, "Academic Research Journal Withoutborders" (ISSN/EISSN 20078870) fue evaluado positivamente en la indexación Citefactor, ahora la página de la revista está disponible en línea, en caso de cualquier problema.

Journals Master | International Innovative Journal Impact Factor (IIJIF)

\section{Red Latinoamericana de revistas Académicas en Ciencias Sociales y Humanidades}
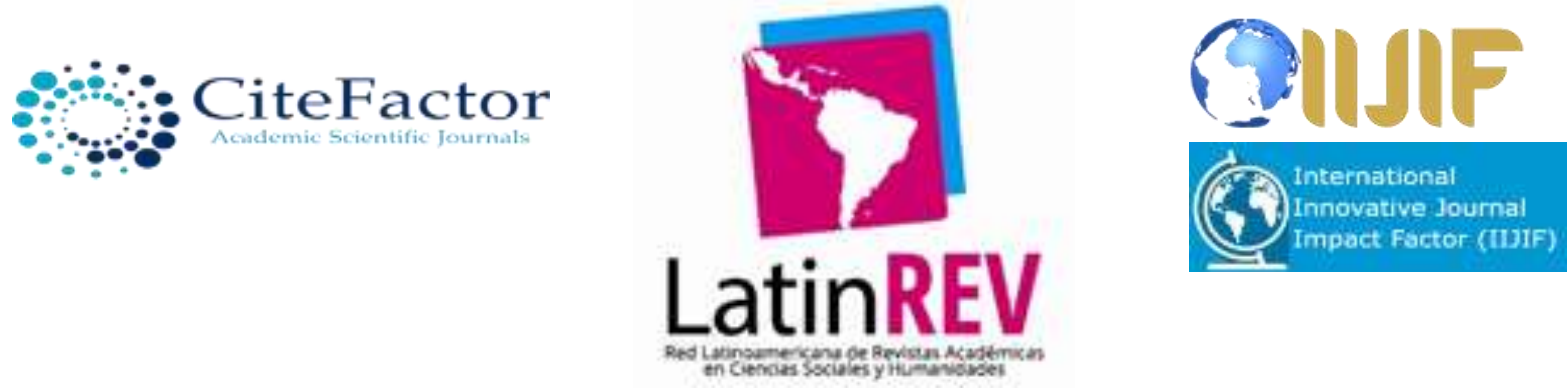
Año 13.

Académica sin Frontera

Núm. 34 Tema COVID 19

Especial

ISSN: 2007-8870

https://revistainvestigacionacademicasinfrontera.unison.mx/index.php/RDIASF

Recibido el 13 de noviembre de 2020. Dictaminado mediante arbitraje favorablemente 30 de diciembre de 2020.

\section{Comité editorial}

\section{Dra. Angélica María Rascón Larios}

Universidad de Sonora. México

Dra. María del Rosario Molina González

Universidad de Sonora

Dra. Francisca Elena Rochin Wong

Universidad de Sonora. México

Dra. Lidia Amalia Zallas Esquer

Universidad de Sonora. México

Dra. Beatriz Llamas Arechiga

Universidad de Sonora. México

\section{Dr. Rogelio Barba Álvarez}

Universidad de Guadalajara. México

Dra. Rosa María Rincón Ornelas

Universidad de Sonora. México

Dr. Juan Flores Preciado

Universidad de Colima. México

Dr. Amado Olivares Leal. Universidad de Sonora

Universidad de Sonora. México

Dr. Guillermo Velázquez Valadez.

Instituto Politécnico Nacional (IPN) México

\section{Dr. Hugo Nefstalí Padilla Torres.}

Universidad Estatal de Sonora. México

Dr. Luis Ramón Moreno Moreno.

Universidad Autónoma de Baja California. México

Dr. Miguel Ángel Vázquez Ruiz.

Universidad de Sonora. México 
"Fl suler ide mis hiips

Año 13.

Núm. 34 Tema COVID 19

Especial
Revista de Investigación

Académica sin Frontera

ISSN: 2007-8870

Recibido el 13 de noviembre de 2020. Dictaminado mediante arbitraje favorablemente 30 de diciembre de 2020.

Dra. Lorena Vélez García.

Universidad Autónoma de Baja California. México

Dra. Pabla Peralta Miranda.

Universidad Simón Bolívar, Barranquilla, Colombia

Mtro. Roberto Espíritu Olmos

Universidad de Colima (FCA Tecomán) Colima

Dr. Héctor Priego Huertas.

Universidad de Colima (FCA Tecomán) Colima

Mtra. María Guadalupe Alvarado Ibarra.

Universidad de Sonora. México.

MSc. Celso Germán Sánchez Zayas

Universidad de Camagüey, Ignacio Agramonte Loynaz, Cuba

Dra. María Luisa Quintero Soto

Universidad Autónoma del Estado de México

Dr. Eyder Bolivar Mojica

Universidad Católica, Luis Amigó, Medellin, Colombia

Revisores de Textos en Inglés

Mtro. Renato Encinas

Mtra. Cecilia Guadalupe Martínez Solano

\section{Comité científico}

Dr. Rosendo Martínez Jiménez. Universidad Autónoma Benito Juárez de Oaxaca.

Dr. Hugo Neftalí Padilla. Universidad Estatal de Sonora

Dra. María Teresa Gaxiola Sánchez. Universidad de Sonora.

Dr. José Cesar Kaplan. Universidad Estatal de Sonora.

Dr. Alfredo Islas Rodríguez. Universidad de Sonora

Frecuencia de publicación: semestral / 2 números por año. 


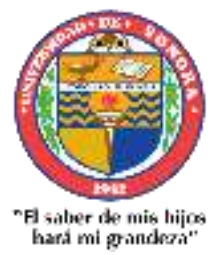

( Julio - Diciembre 2020)

Año 13.

Núm. 34 Tema COVID 19

Especial

https://revistainvestigacionacademicasinfrontera.unison.mx/index.php/RDIASF

Revista de Investigación

Académica sin Frontera

ISSN: 2007-8870

Recibido el 13 de noviembre de 2020. Dictaminado mediante arbitraje favorablemente 30 de diciembre de 2020.

Revista de Investigación Académica sin Frontera (RIASF) con (ISSN: 2007-8870) es un interlocutor internacional de acceso abierto revisado diario en línea en el ámbito del de las Ciencias Económicas Administrativas y Sociales. Su objetivo principal es dar a los trabajos de investigación de calidad. Cubre todas las sub-campos de los campos anteriormente mencionados. Proporciona la plataforma a académicos, estudiantes y profesionales. Sólo pública trabajos de investigación y artículos de revisión inicial. Documento presentado debe cumplir con algunos criterios como, debe ser original, inédita y no estén sometidos a ninguna otra revista.

RIASF es una revista arbitrada / Revisión por pares International. Publicamos documentos sobre una variedad de temas, contextos y estrategias de análisis que examinan la relación entre la rápida evolución para la Sociedad y la tecnología del conocimiento.

REVISTA DE INVESTIGACIÓN ACADÉMICA SIN FRONTERA, Año 13, No. 34, especial, tema COVID. Julio - diciembre 2020, es una publicación semestral de investigación científica, editada por la Universidad de Sonora, a través de las División de Ciencias Económicas y Sociales, de la Unidad Regional Sur, Blvd. Lázaro Cárdenas No. 100, Col. Francisco Villa, Navojoa, Sonora, Sonora, México, C.P. 85880. Tel. (642) 425- 99-54. https://revistainvestigacionacademicasinfrontera.unison.mx/index.php/RDIASF

revistaacademicasinfrontera@unison.mx.

Editor responsable: Francisco Espinoza Morales. Reserva de Derechos al Uso Exclusivo: 04-2013121811323700-203 e ISSN: 2007-8870, ambos otorgados por el Instituto Nacional de Derecho de Autor. Inscrita en el Directorio de LATINDEX, con Núm. De folio 20014, folio único 14590. Responsable de la última actualización de este Número, Unidad Informática de la Universidad de Sonora, fecha de la última modificación, 30 de diciembre 2020, indexada a Cite Factor Academic Scientific Journal y Journals Master (IIJIF) y Red Latinoamericana de Revistas Académicas en Ciencias Sociales y Humanidades, (Latín Rev). Las opiniones expresadas por los autores no necesariamente reflejan la postura del editor de la publicación. Se autoriza la reproducción total o parcial de los contenidos e imágenes en la presente publicación siempre y cuando se cuente con la autorización del editor y se cite plenamente la fuente. 

"Fl sober ile mis hijos
hardi mi gronderis"

Año 13.

Núm. 34 Tema COVID 19

Especial

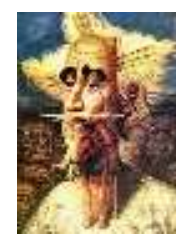

Revista de Investigación

Académica sin Frontera

ISSN: 2007-8870 https://revistainvestigacionacademicasinfrontera.unison.mx/index.php/RDIASF

Recibido el 13 de noviembre de 2020. Dictaminado mediante arbitraje favorablemente 30 de diciembre de 2020.

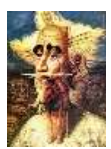

Nos complace anunciar que su diario, "Academic Research Journal Withoutborders" (ISSN/EISSN 20078870) fue evaluado positivamente en la indexación Citefactor, ahora la página de la revista está disponible en línea, en caso de cualquier problema.

Journals Master | International Innovative Journal Impact Factor (IIJIF)

\section{Red Latinoamericana de revistas Académicas en Ciencias Sociales y Humanidades}

CiteFactor

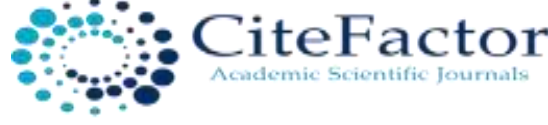

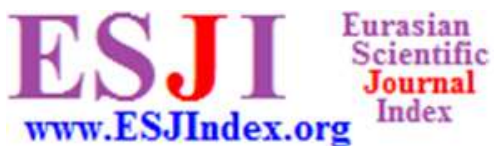

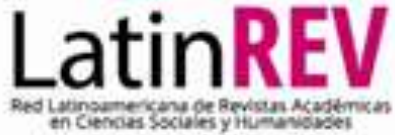

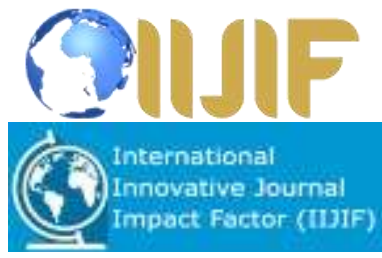

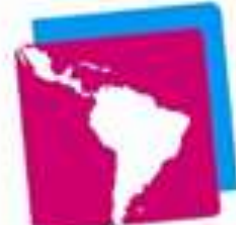

Impact Fsctor (IIIIF)

https://www.neliti.com

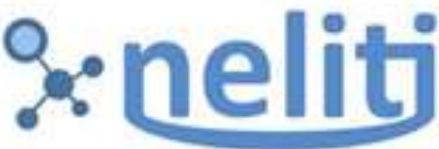

Indonesia's Research Repository

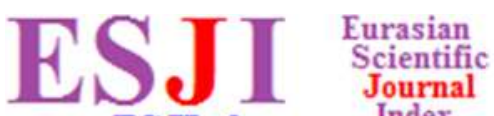

www.ESJIndex.org
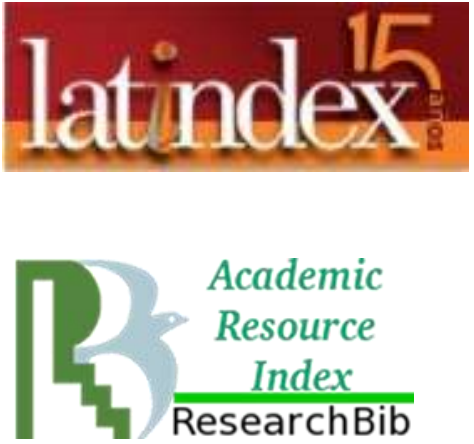